DOI: 10.15290/aipan.2020.04

\title{
Zjawisko niepełnosprawności: od przeszłości ku przyszłości
}

\author{
Andrey Tikhonov \\ Uniwersytet Wrocławski \\ tikhandy@hotmail.com \\ ORCID: https://orcid.org/0000-0001-9391-1003
}

\section{Wprowadzenie}

Uszkodzenia ciała, zaburzenia poznawcze i psychiczne są nieuchronnym elementem funkcjonowania społeczeństwa. Historycznie niepełnosprawność definiowano różnie i stosowano rozliczne rozwiązania mające na celu niwelowanie jej skutków. W XXI w. zjawisko niepełnosprawności wciąż jest problemem aktualnym, a społeczeństwo i rządy stają w obliczu coraz bardziej skomplikowanych wyzwań z nim związanych.

W perspektywie historycznej niepełnosprawność fenomenologicznie jest traktowana zgodnie $\mathrm{z}$ przyjętymi na konkretnym odcinku rozwoju cywilizacyjnego modelami zachowania społecznego i ukształtowanymi nurtami intelektualno-naukowymi, jak np. w starożytnej kulturze greckiej, w której istniało przyzwolenie dla zabijania dzieci z dostrzegalnymi wadami ciała ${ }^{1}$. Tradycyjnie ułomność była przedmiotem kpin, a jednocześnie budziła lęk i litość ${ }^{2}$, „pogłębianą jeszcze przez niektóre passusy biblijne, stwierdzające, że niepełnosprawność jest karą za popełnione grzechy"3. Podobnie jak postrzeganie ludzi, których wygląd fizyczny bądź sposób intelektualno-psychicznego funkcjonowania w znacznym stopniu odbiegały od „normalności”, zostało później utrwalone przez średniowiecznych duchow-

\footnotetext{
1 C. Barnes, G. Mercer, Niepełnosprawność, przekł. P. Morawski, Warszawa 2008, s. 32.

2 J. Ryan, F. Thomas, The Politics of Mental Handicap, Harmondsworth 1980; D. Thomas, The Experience of Handicap, London 1982; C. Barnes, A legacy of oppression: a history of disability in Western culture, [w:] Disability Studies: Past, Present and Future, red. L. Barton, M. Oliver, Leeds 1997.

C. Barnes, G. Mercer, Niepełnosprawność, s. 32.
} 
nych. Pod koniec XVIII oraz w XIX w. osoby z niepełnosprawnościami stały się przedmiotem powstałej w państwach bardziej rozwiniętych biopolityki, wskutek której w trosce o nie zostały powołane liczne instytucje zamknięte. W XX w. ludzkość stanęła w obliczu licznych konfliktów wojennych, klęsk cywilizacyjnych, antyhumanitarnych eksperymentów społecznych, mających uzasadnienie w polityce „higieny społecznej” dotyczącej ludzi z niepełnosprawnościami, jak np. obowiązujące w 1938 r. w 33 stanach USA prawo „zezwalające na przymusową sterylizację kobiet $\mathrm{z}$ upośledzeniem umysłowym" ${ }^{4}$ albo systematyczny program eksterminacji „osób niezasługujących na życie w społeczeństwie” w hitlerowskich Niemczech ${ }^{5}$.

Zarówno dla osób z niepełnosprawnościami, jak i dla badaczy zajmujących się zjawiskiem niepełnosprawności druga połowa XX w. jest znamienna. Po pierwsze, wyodrębniła się samoistna dziedzina naukowa disability studies, umożliwiająca przeprowadzenie badań interdyscyplinarnych. Po drugie, postęp technologiczny oraz podejścia opierające się na koncepcji praw człowieka i samodzielnego funkcjonowania osób z niepełnosprawnościami stworzyły warunki do podniesienia jakości ich życia. Nowe technologie tworzą „dużo lepsze warunki dla niepełnosprawnych, pozwalając im na szersze uczestniczenie w rynku pracy zarobkowej i na stosunkowo samodzielne życie"6. W zmianach tych kluczową rolę odegrał (i nadal ma wielkie znaczenie) ruch o charakterze międzynarodowym, zapoczątkowany przez osoby $\mathrm{z}$ niepełnosprawnościami ${ }^{7}$, którego głównym celem było podważenie głęboko zakorzenionego medycznego dyskursu i postrzeganie niepełnosprawności jako tragedii jednostki ${ }^{8}$. Po trzecie, wyżej wspomniane przemiany, sięgające korzeniami drugiej połowy XX w., nie są jednoznacznie interpretowane przez badaczy, albowiem rzekomo znalezione przez ludzkość equilibrium polityczno-ekonomiczne, głoszone na przykład przez Hannah Arendt, Zbigniewa Brzezińskiego, Francisa Fukuyamę i Samuela Huntingtona, okazały się pozorne. Wbrew oczekiwaniom demokracja, neoliberalizm, gospodarka wolnorynkowa, globalizacja nie tylko nie rozwiązują całego szeregu konfliktów związanych z odmiennością, „nienormalnością”, ale czasem wręcz sprzyjają wyłonieniu się nowych sposobów wykluczenia nosicieli „anormalności” w rozwoju fizycznym bądź intelektualno-psychicznym. Uzasadnionym zatem zdaje się sformułowanie tezy, że przyszłość, w której będą funkcjonowali ludzie z niepełnosprawnościami, może potoczyć się według zupełnie odmiennych scenariuszy.

\footnotetext{
Ibidem, s. 43.

M. Burleigh, Death and Deliverance: "Euthanasia" in Germany 1900-1945, Cambridge 1994, s. 194.

V. Finkelstein, Attitudes and Disabled People, New York 1980, s. 11.

D. Driedger, The Last Civil Rights: Disabled People's International, London 1989.

T. Blackmore, S. Hodgkins, Discourses of disabled peoples' organisations: Foucault, Bourdieu and future perspectives, [w:] Disability and Social Theory. New Developments and Directions, red. D. Goodley, B. Hughes, L. Davis, London 2012, s. 71.
} 


\section{Niepełnosprawność jako osobista tragedia jednostki}

Ogólnie rzecz biorąc, pod koniec XVIII oraz w XIX w. doszło do stworzenia zakrojonego na szeroką skalę systemu kontroli społecznej, który poza szpitalami i domami opieki obejmował także więzienia, przytułki, szkoły i kolonie ${ }^{9}$, stanowiąc - jak uważają badacze - początek uprawiania biopolityki. Wraz ze wzrostem uprzemysłowienia i urbanizacji w Ameryce Północnej i Wielkiej Brytanii rozwinęła się praktyka tworzenia wyspecjalizowanych zakładów dla osób „najbardziej upośledzonych lub groźnych"10. Pewne grupy niepełnosprawnych - zwłaszcza osoby określane jako umysłowo chore - uznawano za problem stanowiący „ciężar” społeczny, który należy izolować w zakładach zamkniętych. Spowodowało to ukrycie ogromnej liczby osób niepełnosprawnych w ośrodkach odosobnienia. Dla uzasadnienia takiego postępowania przywoływano argument, że robi się to dla ich własnego dobra, aby nie stanowili ciężaru dla innych ${ }^{11}$. W zakładach zamkniętych był często bardzo surowy rygor, a długoletni pensjonariusze byli „spisywani na straty” jako „społecznie martwi”, oczekujący w nich jedynie końca swego życia ${ }^{12}$. W taki sposób państwo rozwiązywało problemy zarówno samych niepełnosprawnych, jak i społeczeństwa.

Postrzeganie uszkodzeń ciała albo zaburzeń intelektualnych i psychicznych jako osobistej tragedii jednostki powoduje, iż osoba $\mathrm{z}$ dysfunkcją pozostaje pod opieką pracowników zatrudnionych w wyspecjalizowanych instytucjach zamkniętych oraz traktowana jest jako przedmiot terapii medycznej i rehabilitacji. Definiowanie zjawiska niepełnosprawności wyłącznie przez jej wymiar medyczny i podejście do niepełnosprawności jako osobistej tragedii jednostki legitymizuje działalność wszelkich instytucji dobroczynnych i edukacyjnych, jak również może służyć uzasadnieniu odpowiednich praktyk w psychologii i medycynie. Takie praktyki stosowane były w XIX i na początku XX w. w Europie oraz w Ameryce Północnej, m.in. w Stanach Zjednoczonych, gdzie dopełnione zostały tzw. Prawem o brzydocie (Ugly Laws), nakładającym społeczne ograniczenia na osoby, których wygląd fizyczny był rażący lub mógł wystraszyć „normalnych” ludzi ${ }^{13}$.

Na terytorium podzielonej w XIX w. Polski - jak pisze Ewa Grodecka - powstały szkoły specjalne oraz - używając współczesnych określeń- zakłady aktywi-

9 S. Cohen, A. Scull, Social Control and the State, Oxford 1983.

10 R.A. Parker, An historical background, [w:] Residential Care: the Research Reviewed, red. I. Sinclair, London 1988.

11 E. Goffman, Asylums: Essays on the Social Situation of Mental Patients and Other Inmates, New York 1961.

12 E.J. Miller, G.V. Gwynne, A Life Apart, London 1972.

13 R. Bogdan, The social construction of freaks, [w:] Freakery: Culture Spectacles of the Extraordinary Body, red. R.G. Thomson, New York 1996; D. Gerber, The careers of people exhibited in freak shows: the problem of volition and valorisation, [w:] Freakery: Culture Spectacles of the Extraordinary Body, red. R.G. Thomson, New York 1996. 
zacji zawodowej dla osób niewidomych i słabowidzących ${ }^{14}$. Ich wydajność była znikoma, albowiem brak było przeświadczenia, że osoba niewidoma rzeczywiście jest w stanie nabyć umiejętności i kompetencje pozwalające jej samodzielnie funkcjonować.

Dwudziestowieczna teoria społeczna zwykle podążała za ustawami z zakresu medycyny, określając mianem niepełnosprawnych osoby z fizycznymi, sensorycznymi i poznawczymi zaburzeniami ${ }^{15}$, a zatem niezdolnymi do pełnienia ważnych ról i funkcji społecznych, co czyniło osoby niepełnosprawne zależnymi od ludzi fizycznie zdrowych i społecznie produktywnych ${ }^{16}$. Z punktu widzenia społeczeństwa niepełnosprawność jest zaburzeniem, a „wartości spajające społeczeństwo muszą wspierać interesy i działalność większości, dlatego też promują dynamiczną niezależność i osiągnięcia będące wynikiem współzawodnictwa, zwłaszcza w sferze zawodowej. Ponadto powodują też skutki uboczne, stygmatyzując i tworząc negatywny jego obraz oraz upośledzając ludzi w tych jakże istotnych aspektach życia"17.

Nasilenie oraz forma uprzedzeń wobec osób z niepełnosprawnościami powoduje, że mają one charakter opresji. Wskazuje na to powszechna dyskryminacja przejawiająca się w zabudowie przestrzeni publicznej, zatrudnieniu, wypoczyn$\mathrm{ku}$ i relacjach osobistych. Ludzie niepełnosprawni wpisują się w system wartości „pełnosprawnych”, dopóki są określani jako „cierpiący i schorowani”18. „Bycie postrzeganym jako przedmiot terapii medycznej tworzy obraz złożony z wielu przypisywanych mu cech, takich jak: słabość, bezradność, zależność, regresywność, nienormalność wyglądu i deprecjacja wszystkich sposobów funkcjonowania fizycznego i umysłowego"19.

Zaburzenia kanału sensorycznego, którym jest zmysł wzroku, są przyczyną tylko jednego z wielu rodzajów niepełnosprawności. Wydaje się, że sposób postrzegania tej konkretnej niepełnosprawności oraz definiowanie innych rodzajów zaburzeń i ograniczeń charakteryzuje się wspólnymi cechami w świadomości ludzkiej. Amerykańska badaczka niepełnosprawności Georgina Kleege poddaje analizie pojęcia blind, sight, vision, odtwarzając utrwalone schematy językowe i kulturowe. Brak sposobności widzenia (blindness) w świadomości ludzkiej wiąże się z ciemnością, zależnością, wykluczeniem, bezradnością, potrzebą pomocy, śmiercią, nie-

\footnotetext{
14 E. Grodecka, Historia niewidomych polskich w zarysie, Warszawa 1996.

15 T. Dartington, E.J. Miller, G. Gwynne, A Life Together, London 1981, s. 126.

16 C. Safilios-Rothschild, The Sociology and Social Psychology of Disability and Rehabilitation, New York 1970, s. 12.

17 E. Topliss, Social Responses to Handicap, London 1982, s. 112.

18 P. Hunt, A critical condition, [w:] Stigma: The Experience of Disability, red. P. Hunt, London 1966, s. 155.

19 I.K. Zola, Self identity and the naming question: reflections on the language of disability, „Social Science and Medicine" 1993, nr 36, s. 168.
} 
możnością zrozumienia i doświadczenia czegoś ${ }^{20}$. Osoba niewidoma postrzegana jest jako żebrząca na stacji metra, która osiągnąwszy sukcesy w życiu prywatnym i zawodowym, stanowi wyjątek i przykład bohaterstwa, gdyż udało jej się przezwyciężyć niepełnosprawność ${ }^{21}$, która budzi zarówno lęk, jak i podziw, świadczący o ambiwalentnym stosunku do niej „wśród normalnych” i wskazuje na „kulturową psychopatologię pełnosprawności"22.

\section{Ruch osób z niepełnosprawnościami ku nowemu modelowi}

Protesty osób niepełnosprawnych sięgają korzeniami co najmniej pierwszych dziesięcioleci XX w. Niskopłatna praca i złe warunki przyczyniły się do zmobilizowania w 1920 r. niewidomych robotników z całej Wielkiej Brytanii do marszu na Londyn ${ }^{23}$. W celu przełamywania ugruntowanych stereotypów myślenia i dążąc do niezależnego oraz godnego życia, w pierwszej połowie XX w. osoby z dysfunkcjami uzewnętrzniły swoje pragnienia w protestach i postulatach politycznych. Przykładem może służyć strajk niewidomych pracowników 28 lutego 1939 r., który odbył się w Derry, w Irlandii Północnej, pod hasłem „nie widzimy, ale widzimy istotne rzeczy"24. Od lat 60. XX w. w atmosferze narastania różnych form społecznego protestu zakłady zamknięte stały się miejscem powstającej wspólnej tożsamości osób z niepełnosprawnościami. Powstanie Ruchu Samodzielnego Życia (Independent Living Movement) w Stanach Zjednoczonych było stymulowane przez organizowanie się niepełnosprawnych weteranów wojny w Wietnamie. W awangardzie protestów obejmujących demonstracje przed Białym Domem na rzecz polityki opieki społecznej oraz okupacji budynku Federalnego Biura Transportu, której celem było żądanie bardziej przystosowanych do ich potrzeb autobusów dalekobieżnych, była organizacja Americans Disabled for Attendant Programs Today. Zaowocowało to powstaniem w 1972 r. w Berkley w Kalifornii pierwszego Ośrodka Samodzielnego Życia (Center of Independent Living - CIL), w którym inicjatywę przejęli niepełnosprawni studenci uniwersytetu pod przywództwem Eda Robertsa, umieszczeni przez uczelniane władze „dla ich własnego dobra” w lokalnym szpitalu. Działalność CIL opiera się na trzech podstawowych zasadach:

- niepełnosprawni najlepiej potrafią określić swoje potrzeby i sposób, w jaki powinny one być zaspokajane;

- konieczny jest wszechstronny program wsparcia;

\footnotetext{
20 G. Kleege, Sight Unseen, New Haven-London 1999, s. 18.

21 Ibidem, s. 19.

22 D. Goodley, Disability Studies. Theorising Disablism and Ableism, London-New York 2014.

23 C. Barnes, G. Mercer, Niepełnosprawność, s. 146.

24 M.Ó Catháin, Blind, but not to the hard facts of life: the blind workers' struggle in Derry, 1928-1940, [w:] Radical History Review: Disability History, red. T. Meade, D. Serlin, Durham 2006.
} 
- niepełnosprawni powinni w jak największym stopniu integrować się ze społeczeństwem, w którym żyją ${ }^{25}$.

Kształtował się inny wizerunek osoby z niepełnosprawnością, przedstawianej jako aktywnego uczestnika protestów przeciwko nieprzystosowanym budynkom i komunikacji, cięciom środków na opiekę społeczną, a także uczestnika różnorodnych kampanii na rzecz praw obywatelskich. Te ostatnie obejmowały m.in. przykuwanie się niepełnosprawnych do autobusów i pociągów, blokowanie dróg oraz czołganie się po ulicach ${ }^{26}$.

W literaturze za przełomowy moment w historii niepełnosprawności uważa się list, który Paul Hunt w 1972 r. skierował do gazety „The Guardian”27, co wpłynęło na powstanie Związku Niepełnosprawnych Fizycznie Przeciwko Segregacji (Union of the Physically Impaired Against Segregation - UPIAS). Manifest tej organizacji pt. Fundamental Principles of Disability zawierał fundamentalne stwierdzenie: „z naszej perspektywy, to społeczeństwo upośledza osoby niepełnosprawne fizycznie"28. W krajach bardziej demokratycznych grupy niepełnosprawnych naśladowały wzajemnie swoją taktykę, stosując kampanie wykorzystujące akcję bezpośrednią do okupacji budynków rządowych oraz zakłócając system komunikacji i medialne wydarzenia. W Wielkiej Brytanii Sieć Akcji Bezpośredniej (Direct Action Network - DAN) organizowała kampanie protestacyjne odbywające się przed budynkami rządowymi, na ulicach oraz $\mathrm{w}$ środkach transportu, co przyciągało uwagę publiczną. Takie wydarzenia pokazywały „środkowy palec tradycyjnemu, wykreowanemu przez akcje charytatywne wizerunkowi niepełnosprawnego jako cichego, poważnego i uległego"29. W Australii w 1997 r. doszło do okupacji kancelarii premiera w proteście przeciw cięciom budżetowym dla Komisji Praw Człowieka i Równych Szans ${ }^{30}$. W krajach mających odmienne systemy polityczne zarządzanie niepełnosprawnością zostało zmonopolizowane przez instytucje państwowe, a nieposłuszeństwo obywatelskie wyrażające się w akcjach protestacyjnych zostało zdecydowanie stłumione. Nie oznacza to, że na przykład w republikach Związku Radzieckiego nie działali aktywiści z niepełnosprawnościami, jednakże ich działalność była dostosowana do ówczesnych warunków.

Centre for Independent Living. Independent living: the right to choose, [w:] Disabled People as Second-Class Citizen, red. M. Eisenberg et al., New York 1982, s. 250-251.

6 A. Pointon, Out of the closet: new images of disability in the civil rights campaign, [w:] Social Policy, the Media and Misrepresentation, red. B. Franklin, London 1999.

D. Pfeiffer, A Comment on the social model(s), „Disability Studies Quarterly” 2000, nr 22(4); T. Shakespeare, Disability Rights and Wrongs, London 2006, s. 14.

UPIAS, Fundamental Principles of Disability, London 1976, s. 14.

C. Daniel, Radical, angry and willing to work, „New Statesman” 1998, 6 March, s. 22.

B.J. Gleeson, Geographies of Disability, Routledge-London 1999. 
Wielu autorów i badaczy zajmujących się zjawiskiem niepełnosprawności dostrzega ruch społeczny zapoczątkowany przez same osoby z niepełnosprawnościami, który przyjął perspektywę ponadnarodową ${ }^{31}$, jako jedną z kluczowych przyczyn poprawy ogólnych warunków życia tej grupy społecznej. Podważywszy głęboko zakorzeniony medyczny model niepełnosprawności, ruch emancypacyjny osób z niepełnosprawnościami przyczynił się do powstania społeczno-politycznego modelu.

Sposób definiowania niepełnosprawności powinien uwzględniać wielowymiarowy charakter tego zjawiska, czyli nie tylko uszkodzenia, zaburzenia albo brak funkcji ciała ludzkiego, ale również różnorodne bariery, które utrudniają bądź wręcz uniemożliwiają samodzielne funkcjonowanie osoby z niepełnosprawnością. W 1978 r. Frank Bowe wskazał sześć największych przeszkód we włączeniu osób niepełnosprawnych do życia społecznego: bariery architektoniczne, bariery związane $\mathrm{z}$ postawą wobec inności, bariery edukacyjne, zawodowe, prawne i osobiste (od skromnych zasobów materialnych po stygmatyzację) $)^{32}$. Rozróżnienie uszkodzeń i barier, które osoba napotyka w społeczeństwie, pozwala zbudować „model barier społecznych” czy też „społeczny model” niepełnosprawności ${ }^{33}$. Na przykład wada wzroku jest upośledzeniem funkcjonowania organizmu (impairment), które powoduje niepełnosprawność funkcjonalną (functional disabbility) wynikającą z trudności wykonywania codziennych czynności (samodzielne poruszanie się, korzystanie z środków komunikacji miejskiej, czytanie etc.) ${ }^{34}$. Z kolei upośledzenie lub niepełnosprawność społeczna (handicap) oznacza mniej uprzywilejowaną lub mniej korzystną sytuację danej osoby, która ogranicza lub uniemożliwia jej pełnienie ról związanych z jej wiekiem, płcią oraz sytuacją społeczną i kulturową ${ }^{35}$.

Socjopolityczny model niepełnosprawności opiera się na koncepcji, zgodnie z którą to nie uszkodzenia ciała albo umysłu determinują problemy osób z niepełnosprawnościami, lecz niemożność zaspokojenia potrzeb takich ludzi przez społeczeństwo $^{36}$. Niepełnosprawność definiuje się jako niekorzyści lub ograniczenia aktywności spowodowane współczesną organizacją społeczeństwa, które nie bierze pod uwagę ludzi niepełnosprawnych fizycznie, wykluczając ich z udziału w głównym nurcie życia społecznego ${ }^{37}$. Światowa Organizacja Zdrowia poprzez wydanie International Classification of Impairments, Disabilities and Handicaps w 1980 r. przyczyniła się do promowania, akceptacji i wdrażania w życie nowej definicji.

\footnotetext{
31 M. Oliver, Understanding Disability: From Theory to Practise, Basingstoke 1996.

32 F. Bowe, Handicapping America, New York 1978.

33 V. Finkelstein, Disability: a social challenge or an administrative responsibility?, [w:] Disabling Barriers Enabling Environments, red. J. Swain et al., London 1993.

34 C. Barnes, G. Mercer, Niepełnosprawność, s. 21.

35 WHO, International Classification of Impairments, Disabilities and Handicaps, 1980, s. 29.

36 V. Finkelstein, Disability: a social challenge...

37 UPIAS, Fundamental..., s. 3-4.
} 


\section{Czy niepełnosprawność nadal istnieje?}

Osoby z niepełnosprawnościami wywalczyły sobie prawo głosu w procesie podejmowania decyzji, które ich dotyczą. „Nic o nas bez nas” - to tradycyjne hasło protestów regularnie odbywających się w różnych krajach.

Dzięki aktywizmowi osób z niepełnosprawnościami powstały liczne organizacje pozarządowe, które są zarządzane przez samych beneficjariuszy, czyli odbiorców świadczonych przez nie usług. Trudno przecenić znaczenie organizacji pozarządowych, które odegrały w rozpowszechnieniu i wdrożeniu socjopolitycznego modelu niepełnosprawności ${ }^{38}$, jak również w uznaniu niepełnosprawności jako tożsamości zbiorowej osób z niepełnosprawnościami jako mniejszości, od lat kojarzonej z dyskryminacją i wykluczeniem ich roli. Organizacje pozarządowe stwarzają warunki do rozwoju takich osób, przyczyniając się do poszukiwania rozwiązań systemowych, realizując projekty mające na celu promowanie i wspieranie inkluzji i równości ${ }^{39}$.

W obronie praw osób niepełnosprawnych na poziomie międzynarodowym i krajowym zostały przyjęte antydyskryminacyjne akty prawne oraz stworzono instytucje do egzekwowania tego prawa. W USA batalie prawnicze dotyczące naruszania praw konstytucyjnych osób z niepełnosprawnościami, zainteresowanie tym tematem mediów i zwiększenie publicznej świadomości w walce o prawa niepełnosprawnych ostatecznie zakończyły się uchwaleniem w 1990 r. ustawy o niepełnosprawności - Americans with Disabilities Act - ADA, stanowiącej najstarszy i najbardziej wszechstronny na świecie akt prawa przeciwdziałającego dyskryminacji niepełnosprawnych ${ }^{40}$. W 1985 roku Kanada wpisała niepełnosprawność jako kategorię związaną z prawami człowieka w Canadian Charter of Rights and Freedoms. W 1992 r. uchwalono Australian Disability Discrimination Act. W 1993 r. włączono zapis o dyskryminacji niepełnosprawnych w Human Rights Act in New Zeland, a w 1995 r. przyjęto Disability Discrimination Act w Wielkiej Brytanii. W polskim prawie antydyskryminacyjnym kluczowa jest ustawa $\mathrm{z}$ dnia 27 sierpnia 1997 roku o rehabilitacji zawodowej i społecznej oraz zatrudnianiu osób niepełnosprawnych. Podstawowy międzynarodowy antydyskryminacyjny akt prawny sporządzono 13 grudnia 2006 r. w Nowym Jorku. Była to Konwencja ONZ o prawach osób niepełnosprawnych, a trzy lata później, 13 marca 2019 r., Parlament Europejski zatwierdził Europejski Akt o Dostępności - dyrektywę, której celem jest stworzenie wspólnych dla całej Unii Europejskiej standardów dóbr i usług dostosowanych do potrzeb osób z różnymi niepełnosprawnościami.

38 C. Barnes, G. Mercer, Niepełnosprawność, s. 18.

39 T. Blackmore, S. Hodgkins, Discourses of disabled..., s. 72.

40 B. Doyle, From welfare to disability and legal change in the United Kingdom in the late 1990s, [w:] Disability, Diversability and Legal Change, red. M. Jones, L. Marks, The Hague 1999, s. 209-226. 
W różnym stopniu, w zależności od wielu czynników, polityka społeczna wobec osób z niepełnosprawnościami w różnych krajach kształtuje się w oparciu o koncepcję, że państwo jest „współtwórcą warunków, w których jednostka odnajduje dla siebie możliwości zaspokajania swoich potrzeb, rozwoju osobistego i zbiorowego" 41 . $\mathrm{W}$ tym celu powstają fundusze, $\mathrm{z}$ których mogą korzystać instytucje działające na rzecz osób z niepełnosprawnościami, umożliwiając im kosztowną i długotrwałą rehabilitację, zaopatrzenie w sprzęt wspomagający, zatrudnienie, kształcenie, rozwój osobisty i zawodowy. Sprzyja to zwiększonemu uczestnictwu osób z niepełnosprawnościami w życiu publicznym i kulturalnym, jak również wzrostowi liczby zatrudnionych oraz podejmujących naukę na studiach wyższych.

Wydawałoby się, że w skali międzynarodowej, jak również w poszczególnych krajach, sytuacja osób $\mathrm{z}$ niepełnosprawnościami wygląda wzorowo, co wynika $\mathrm{z}$ możliwość korzystania $\mathrm{z}$ różnorodnych rozwiązań instytucjonalnych, prawnych, medycznych oraz „nowoczesnych technicznych środków przywrócenia sprawności” ${ }^{42}$. Jednak bardziej wnikliwa interpretacja rzeczywistości pozwala zauważyć mankamenty, które mogą zdeterminować przyszłość ludzi głuchych, niewidomych, poruszających się na wózkach, niskiego wzrostu czy z zespołem Downa etc.

Zasadniczym problemem, którego nie da się w całości rozwiązać, jest sposób tworzenia całej złożonej i emergentnej rzeczywistości, w której ludzie funkcjonują. Analizując ten fenomen z perspektywy osoby całkowicie niewidomej, Georgina Kleege stwierdza: że „język, którego używam, literatura, którą czytam, sztuka, którą cenię, historia, której się uczyłam w szkole, architektonika, w której mieszkam, urządzenia, z których korzystam, to wszystko zostało stworzone przez ludzi widzących i dla ludzi widzących"43. Rzeczywistość człowieka, społeczno- i gospodarczo-polityczne modele funkcjonowania, szeroko rozumiana infrastruktura są konstruowane w oparciu o założenie, iż będą postrzegane, wykorzystywane i modyfikowane przez psychosomatyczne jednostki w pełni umysłowo, psychicznie i fizycznie sprawne. Osiągnięcia cywilizacyjne, takie jak socjopolityczny model niepełnosprawności, rozwiązania instytucjonalno-prawne, techniczne i medyczne, służą temu, aby owa rzeczywistość charakteryzowała się jak najmniejszą liczbą barier, które są przyczyną niepełnosprawności funkcjonalnej i społecznej. Chociaż w pełni nie sposób ich wyeliminować, ambitnym zadaniem powinno być dążenie do stanu idealnego.

Warto także zwrócić uwagę na medyczny wymiar niepełnosprawności. Obecny stan wiedzy w zakresie medycyny, technologie i umiejętności specjalistyczne po-

\footnotetext{
41 A. Zybała, Państwo i społeczeństwo w działaniu. Polityki publiczne wobec potrzeb modernizacji państwa i społeczeństwa, Warszawa, 2013, s. 27.

42 A. Tikhonov, Nowoczesne techniczne środki przywrócenia sprawności w życiu osób z wadami wzroku, [w:] Niepełnosprawność w socjologii. Stan obecny i perspektywy rozwoju, red. Ł. Koperski, Poznań 2019, s. 257-271.

43 G. Kleege, Sight Unseen, s. 3.
} 
zwalają - ale nie we wszystkich wypadkach - częściowo „naprawić”, albo w pełni przywrócić uszkodzoną funkcję organizmu. Istnieje więcej możliwości uratowania albo przedłużania życie pacjentom, którzy wcześniej nie mieliby szans. Z jednej strony, rozpatrując tę kwestię z punktu widzenia myśli humanistycznej i biopolityki państwa, zdecydowanie jest to doniosłym osiągnięciem, jako że życie każdego człowieka jest wartościowe, a państwo potrzebuje jak najwięcej zdrowych i zdolnych do pracy, czyli do zapewnienia dobrobytu własnego i innych członków społeczeństwa obywateli. Z drugiej strony po bezpośredniej terapii medycznej ludzie często potrzebują długotrwałej rehabilitacji i wsparcia ekonomiczno-społeczno-psychologicznego, co oznacza zwiększenie wydatków z budżetu państwa. „Niebawem staniemy w obliczu poważnego wyzwania i zaciętych dyskusji na temat niepełnosprawności", spowodowanych spowolnieniem rozwoju gospodarki i ewentualnymi kryzysami finansowymi ${ }^{44}$.

Siłą napędową funkcjonowania krajów zachodnich są wartości neoliberalne, w związku z czym, jak twierdzi Fukuyama, „po raz pierwszy pojawiła się możliwość uniwersalizacji zachodniej liberalnej demokracji jako ostatecznej formy rządu" 45 . Te wartości na ogół są popierane i promowane przez społeczeństwa tych krajów. Badacze zajmujący się zjawiskiem niepełnosprawności dostrzegają, że doprowadza to do idealizacji „neoliberalnej sprawności” (neoliberal-ableism), jako że to sprawność umożliwia rozwój, bogacenie się i pełne uczestnictwo w życiu ${ }^{46}$. „Zgodnie z koncepcją liberalizmu natura ludzka jest zasadniczo dobra, a ludzie mogą poprawiać swoje warunki moralne i materialne, umożliwiając w ten sposób postęp społeczny” ${ }^{47}$. Konflikt tkwi w tym, iż nie wszyscy ludzie są w stanie na przykład „pracować osiem godzin dziennie, a wieczorami grać w badmintona”" ${ }^{4}$, czyli ze względu na stan zdrowia nie mogą dostosować się do zasad narzucanych przez zinstytucjonalizowane formy neoliberalizmu i hiperkapitalizmu. W neoliberalnej rzeczywistości „przywileje ma sprawność cielesna” (able-bodiedness), a wymaganą i pożądaną przez rynek normą są „niezależni, autonomiczni obywatele” ${ }^{49}$. W takiej sytuacji uzasadniona wydaje się być teza, że źródłem społecznego upośledzenia i niepełnosprawności jest rozwój gospodarczy, technologiczny i kulturalny w zachodnim stylu $^{50}$. Industrializacja, urbanizacja, liberalny utylitaryzm i medykalizacja wraz z kulturowym znaczeniem, jakie niesie rozpowszechniane przede wszystkim w zachodnich mediach pojęcie „pełnosprawnej normalności”, wpłynęły na społeczną

\footnotetext{
44 D. Goodley, Disability Studies..., s. 14.

45 F. Fukuyama, Koniec historii [przekł. B. Stanosz], [w:] Czy koniec historii?, red. I. Lasota, Warszawa 1991, s. 8.

46 D. Goodley, Disability Studies..., s. 35-51.

47 K. Mingst, Podstawy stosunków międzynarodowych, przekł. M. Habura, G. Łuczkiewicz, Warszawa 2006, s. 22.

48 S. Vasey, A Response to Liz Crow, „Coalition” 1992, September, s. 44.

49 D. Goodley, Disability Studies..., s. 120.

50 C. Barnes, G. Mercer, Niepełnosprawność..., s. 167.
} 
konstrukcję niepełnosprawności. Jest to przyczyną systematycznego wykluczania osób z niepełnosprawnościami.

\section{Podsumowanie}

Niepełnosprawność jest zjawiskiem wielowymiarowym, przedmiotem badań interdyscyplinarnych i niezbędnym elementem współczesnej polityki. Na różnych etapach rozwoju ludzkości osoby z niepełnosprawnościami były traktowane różnie; stosowano różne rozwiązania w celu niwelowania skutków niepełnosprawności: zabijanie, przymusową sterylizację, umieszczanie w zakładach zamkniętych. Emancypacyjny ruch osób z niepełnosprawnościami XX w. doprowadził do powstania, rozpowszechnienia i wdrażania w życie społeczno-politycznego modelu, co przyczyniło się do podniesienia ich jakości życia. Nader ważnym osiągnięciem cywilizacyjnym jest to, że w XXI w. osoba niepełnosprawna może korzystać z wielorakich rozwiązań instytucjonalno-prawnych, technicznych i medycznych, mających na celu przywracanie jej sprawności. Jednak zjawisko niepełnosprawności pomimo radykalnych zmian w traktowaniu zaburzeń fizycznych, umysłowych i psychicznych oraz podniesienia jakości życia osób z niepełnosprawnością, mimo przyjętych antydyskryminacyjnych aktów prawnych na poziomie krajowym i międzynarodowym, mimo rozwoju medycyny, nauk społecznych i technologii - nadal stanowi wyzwanie dla ludzkości.

W erze późnej nowoczesności i globalizacji, rozumianej jako wyraz fundamentalnych aspektów rozsuwania czasu i przestrzeni ${ }^{51}$, w dobie ponowoczesności charakteryzującej się malejącym znaczeniem legitymizacji politycznej, ideologii i dominującej kultury oraz poszukiwaniem przyjemności z konsumpcji ${ }^{52}$, w rzeczywistości konstruowanej w oparciu o „neoliberalną sprawność”, „sprawność cielesną”, „pełnosprawną normalność” osoba z niepełnosprawnością może czuć się jeszcze bardziej zagubiona i wyalienowana.

Czy ludzkość poradzi sobie z tym problemem? Czy istnieje możliwość powrotu do eugeniki i darwinizmu społecznego? Jak potoczy się los osób z niepełnosprawnościami, kiedy państwa bezpośrednio staną w obliczu problemów związanych ze zmianami klimatu, zanieczyszczeniami środowiska, poważnymi globalnymi kryzysami finansowymi albo jakimikolwiek innymi zagrożeniami bezpieczeństwa państwa lub ludzkości? Czy można wykluczyć przyszłe populistyczno-utylitarne nurty namawiające do ostrego cięcia wydatków na wsparcie osób z niepełnosprawnościami? A być może rozwój medycyny i techno-

\footnotetext{
51 A. Giddens, Nowoczesność i tożsamość, przekł. A. Szulżycka, Warszawa 2001, s. 31.

52 Z. Bauman, Ponowoczesność jako źródło cierpień, Warszawa 2000, s. 100.
} 
logii opartych na sztucznej inteligencji sprawi, że niepełnosprawność przestanie istnieć jako zjawisko?

\section{Literatura}

Barnes C., A legacy of oppression: a history of disability in Western culture, [w:] Disability Studies: Past, Present and Future, red. L. Barton M. Oliver, Leeds 1997.

Barnes C., Mercer G., Niepetnosprawność, przekł. P. Morawski, Warszawa 2008.

Bauman Z., Ponowoczesność jako źródło cierpień, Warszawa 2000.

Blackmore T., Hodgkins S., Discourses of Disabled Peoples' Organisations: Foucault, Bourdieu and future perspectives, [w:] Disability and Social Theory. New Developments and Directions, red. D. Goodley, B. Hughes, L. Davis, London 2012.

Bogdan R., The social construction of freaks, [w:] Freakery: Culture Spectacles of the Extraordinary Body, red. R.G. Thomson, New York 1996.

Bowe F., Handicapping America, New York 1978.

Burleigh M., Death and Deliverance: "Euthanasia" in Germany 1900-1945, Cambridge 1994.

Centre for Independent Living. Independent living: the right to choose, [w:] Disabled People as Second-Class Citizens, red. M. Eisenberg et al., New York 1982.

Cohen S., Scull A., Social Control and the State, Oxford 1983.

Daniel C., Radical, angry and willing to work, „New Statesman” 1998, 6 March.

Dartington T., Miller E.J., Gwynne G., A Life Together, London 1981.

Doyle B., From welfare to disability and legal change in the United Kingdom in the late 1990s, [w:] Disability, Diversability and Legal Change, red. M. Jones, L. Marks, The Hague 1999.

Driedger D., The Last Civil Rights: Disabled People's International, London 1989.

Finkelstein V., Attitudes and Disabled People, New York 1980.

Finkelstein V., Disability: a social challenge or an administrative responsibility?, [w:] Disabling Barriers - Enabling Environments, red. J. Swain et al., London 1993.

Fukuyama F., Koniec historii [przekł. B. Stanosz], [w:] Czy koniec historii?, red. I. Lasota, Warszawa 1991.

Gerber D., The careers of people exhibited in freak shows: the problem of volition and valorisation, [w:] Freakery: Culture Spectacles of the Extraordinary Body, red. R.G. Thomson, New York 1996.

Giddens A., Nowoczesność i tożsamość, przekł. A. Szulżycka, Warszawa 2001.

Gleeson B.J., Geographies of Disability, London 1999.

Goffman E., Asylums: Essays on the Social Situation of Mental Patients and Other Inmates, New York 1961.

Goodley D., Disability Studies. Theorising Disablism and Ableism, London-New York 2014.

Grodecka E., Historia niewidomych polskich w zarysie, Warszawa 1996. 
Hunt P., A critical condition, [w:] Stigma: The Experience of Disability, red. P. Hunt, London 1966.

Kleege G., Sight Unseen, New Haven-London 1999.

Miller E.J., Gwynne G.V., A Life Apart, London1972.

Mingst K., Podstawy stosunków międzynarodowych, przekł. M. Habura, G. Łuczkiewicz, Warszawa 2006.

Oliver M., Understanding Disability: From Theory to Practise, Basingstoke 1996.

Ó Catháin, M., Blind, but not to the hard facts of life: the blind workers' struggle in Derry, 1928-1940, [w:] Radical History Review: Disability History, red. T. Meade, D. Serlin, Durham 2006.

Parker R.A., An historical background, [w:] Residential Care: the Research Reviewed, red. I. Sinclair, London 1988.

Pfeiffer D., A Comment on the social model(s), „Disability Studies Quarterly” 2000, nr 22(4).

Pointon A., Out of the closet: new images of disability in the civil rights campaign, [w:] Social Policy, the Media and Misrepresentation, red. B. Franklin, London 1999.

Ryan J., Thomas F., The Politics of Mental Handicap, Harmondsworth 1980.

Safilios-Rothschild C., The Sociology and Social Psychology of Disability and Rehabilitation, New York 1970.

Shakespeare T., Disability Rights and Wrongs, London 2006.

Thomas D., The Experience of Handicap, London 1982.

Tikhonov A., Nowoczesne techniczne środki przywrócenia sprawności w życiu osób z wadami wzroku, [w:] Niepetnosprawność w socjologii. Stan obecny i perspektywy rozwoju, red. Ł. Koperski, Poznań 2019.

Topliss E., Social Responses to Handicap, London 1982.

UPIAS, Fundamental Principles of Disability, London 1976.

Vasey S., A Response to Liz Crow, „Coalition” 1992, September.

WHO, International Classification of Impairments, Disabilities and Handicaps, 1980.

Zola I.K., Self identity and the naming question: reflections on the language of disability, „Social Science and Medicine" 1993, nr 36.

Zybała A., Państwo i społeczeństwo w działaniu. Polityki publiczne wobec potrzeb modernizacji państwa i społeczeństwa, Warszawa 2013. 